\title{
Course of objective memory impairment in non- demented subjects attending a memory clinic and predictors of outcome
}

Citation for published version (APA):

Visser, P. J., Verhey, F. R. J., Ponds, R. W. H. M., Cruts, M., van Broeckhoven, C., \& Jolles, J. (2000). Course of objective memory impairment in non-demented subjects attending a memory clinic and predictors of outcome. International Journal of Geriatric Psychiatry, 15(4), 363-372. https://doi.org/10.1002/(SICI)1099-1166(200004)15:4<363::AID-GPS129>3.0.CO;2-4

Document status and date:

Published: 01/01/2000

DOI:

10.1002/(SICI)1099-1166(200004)15:4<363::AID-GPS129>3.0.CO;2-4

Please check the document version of this publication:

- A submitted manuscript is the version of the article upon submission and before peer-review. There can be important differences between the submitted version and the official published version of record.

People interested in the research are advised to contact the author for the final version of the publication, or visit the DOI to the publisher's website.

- The final author version and the galley proof are versions of the publication after peer review.

- The final published version features the final layout of the paper including the volume, issue and page numbers.

Link to publication

\footnotetext{
General rights rights.

- You may freely distribute the URL identifying the publication in the public portal. please follow below link for the End User Agreement:

www.umlib.nl/taverne-license

Take down policy

If you believe that this document breaches copyright please contact us at:

repository@maastrichtuniversity.nl

providing details and we will investigate your claim.
}

Copyright and moral rights for the publications made accessible in the public portal are retained by the authors and/or other copyright owners and it is a condition of accessing publications that users recognise and abide by the legal requirements associated with these

- Users may download and print one copy of any publication from the public portal for the purpose of private study or research.

- You may not further distribute the material or use it for any profit-making activity or commercial gain

If the publication is distributed under the terms of Article 25fa of the Dutch Copyright Act, indicated by the "Taverne" license above, 


\title{
COURSE OF OBJECTIVE MEMORY IMPAIRMENT IN NON-DEMENTED SUBJECTS ATTENDING A MEMORY CLINIC AND PREDICTORS OF OUTCOME
}

\author{
PIETER JELLE VISSER ${ }^{1 *}$, FRANS R. J. VERHEY ${ }^{1}$, RUDOLF W. H. M. PONDS ${ }^{1}$, MARC CRUTS ${ }^{2}$, \\ CHRISTINE L. VAN BROECKHOVEN ${ }^{2}$ AND JELLEMER JOLLES ${ }^{1}$ \\ ${ }^{1}$ Department of Psychiatry and Neuropsychology, Institute of Brain and Behavior, University of Maastricht, \\ Maastricht, The Netherlands \\ ${ }^{2}$ Department of Molecular Genetics, Flanders Interuniversity Institute for Biotechnology (VIB), Laboratory of \\ Neurogenetics, Born-Burge Foundation (BBS), University of Antwerp (UIA), Department of Biochemistry,
} Antwerp, Belgium

\begin{abstract}
The aim of the study was to investigate the course of objective memory impairment in non-demented subjects who attended a memory clinic and to test predictors of outcome. Non-demented subjects $(N=74)$ were included when they were older than 40 years and had a baseline score on the delayed recall of a word learning test below the tenth percentile. Subjects with memory impairment due to known somatic or neurological causes were excluded. The subjects were reassessed after 2 and 5 years. At the 5 -year follow-up, $42 \%$ of the subjects had no memory impairment, $19 \%$ of the subjects had memory impairment without dementia, and $39 \%$ of the subjects had Alzheimer type dementia (AD). Predictors at baseline of reversible memory impairment in a multivariate analysis were age, scores on the MMSE and delayed recall, and the degree of functional impairment. Predictors at baseline of AD in a multivariate analysis were age and the score on the MMSE. The apolipoprotein E genotype and the presence of depression at baseline were not predictors of outcome. The positive predictive value was $72 \%$ for reversible memory impairment and $81 \%$ for AD. Memory impairment is often reversible and therefore its presence alone is not sufficient to consider subjects as preclinically demented. Predictive accuracy can be increased by including simple measures such as age, the scores on the MMSE and delayed recall, and the degree of functional impairment. Copyright (C) 2000 John Wiley \& Sons, Ltd.
\end{abstract}

KEY WORDS - memory impairment; cognitive impairment no dementia (CIND); Alzheimer's disease; longitudinal

Objective memory impairment in non-demented elderly individuals is an important risk factor for Alzheimer-type dementia (AD) (Bowen et al., 1997; Linn et al., 1995), but cognitive impairment may also be reversible (Alexopoulos et al., 1993; O'Connor et al., 1990). While several studies have investigated the relation between subjective or objective memory impairment and subsequent dementia (Bowen et al., 1997; Coria et al., 1995; O'Brien et al., 1992), there have been no studies on how often objective memory impairment in non-

\footnotetext{
*Correspondence to: Dr. P. J. Visser, Department of Psychiatry, Academisch Ziekenhuis Maastrict, PO Box 5800, 6202 AZ Maastricht, The Netherlands. Fax: +31 43 3875444. e-mail: pj.visser@np.unimaas.nl

Copyright (C) 2000 John Wiley \& Sons, Ltd.
}

demented subjects is reversible and on factors that are associated with the reversibility of memory impairment. It is important to distinguish subjects with reversible memory impairment from those who are at high risk for $\mathrm{AD}$, because high-risk subjects may be candidates for treatment with drugs that are becoming available for AD. In addition, the caregivers of these patients may benefit from counselling on how to handle the cognitive impairment of their partners.

The aim of the present longitudinal study was to investigate the course of memory impairment and to identify predictors of outcome. Outcome was defined as reversible memory impairment, persistent memory impairment without dementia, or AD. We also developed post-hoc decision rules that can

Received 16 June 1999 Accepted 7 September 1999 
be used in clinical practice to predict outcome. We selected variables that have been demonstrated to be associated with an increased risk for AD or cognitive decline in non-demented elderly subjects, e.g. the severity of the memory impairment (Jacobs et al., 1995; Linn et al., 1995), age (Ott et al., 1998), the apolipoprotein E (apoE)-e4 allele (Coria et al., 1995; Petersen et al., 1995; Slooter et al., 1998), the score on the Mini-Mental State Examination (MMSE) (Braekhus et al., 1995), and the degree of interference that cognitive impairment has on the activities of daily living (Brayne et al., 1997). We also selected depression as a predictor because depression may cause cognitive impairment that it reversible after improvement of the depression (Alexopoulos et al., 1993; Hill et al., 1992).

\section{METHODS}

\section{Subjects}

The patients were selected from the Maastricht Memory Clinic, a university-affiliated outpatient clinic for subjects with cognitive impairment (Verhey et al., 1993). All patients complained about memory dysfunction and were referred by a general practitioner $(51 \%)$, a neurologist $(27 \%)$, or a psychiatrist $(22 \%)$. Subjects were included when they were older than 40 years and when they had memory impairment. Memory impairment was defined as an impairment on the delayed recall of a word learning test because several studies indicated that impairment on the delayed recall in particular is predictive of subsequent dementia (Almkvist et al., 1998; Bowen et al., 1997; Linn et al., 1995; Tierney et al., 1996). Impairment was defined as a score below the 10th percentile because this cutoff is commonly used in clinical practice and is similar to the cut-off used in criteria of mild cognitive impairment (Levy, 1994; Smith et al., 1996). This definition of memory impairment excluded most subjects with age-related cognitive decline (ARCD) (American Psychiatric Association, 1994), because the memory impairment was outside the normal limits given the person's age. We excluded subjects with dementia, a score on the MMSE below 24, a score on the Global Deterioration Scale (GDS) (Reisberg et al., 1982) higher than 3, severe sensory impairment, psychosis, panic disorder, post-traumatic stress disorder, bipolar disorder, or cognitive problems in relation to cerebro-vascular events, neurodegenerative diseases (e.g. Parkinson's disease), brain neoplasm, head trauma, drug intoxication, alcohol abuse, hypothyroid or hyperthyroid function, or vitamin deficiency. The study cohort consisted of 74 subjects. After the study was explained to them, subjects gave their written informed consent.

\section{Baseline assessment and clinical diagnosis}

All subjects underwent a standardized assessment at baseline which included a detailed history provided by the patient and a significant other, a psychiatric, neurological, and physical examination, appropriate laboratory tests, a neuropsychological assessment, and neuroimaging as described elsewhere (Verhey et al., 1993). In addition, the MMSE (Folstein et al., 1975), as a measure of global cognitive impairment, the GDS (Reisberg et al., 1982), which is a scale for staging levels of cognitive impairment, the Hamilton Depression Rating Scale-17 items (HDRS) (Hamilton, 1960), and the Blessed Dementia Rating Scale (BDRS) part I (Blessed et al., 1968) were administered. From the BDRS we used the total score on the first 11 items as a measure of impairment in functioning in daily living (BDRS-DL). Psychiatric diagnoses were made according to DSM-IV criteria (American Psychiatric Association, 1994). Depression was diagnosed when the subjects fulfilled the criteria of minor or major depression. The diagnosis of depression was made regardless of a possible underlying aetiology, such as bereavement, co-morbid conditions or pain. Since cognitive impairment in depression is associated with the severity of the depression (Christensen et al., 1997), we have used the term depression in the present study to refer to subjects with a score on the HDRS higher than 13. None of these subjects were severely depressed, as HDRS scores were lower than 26. All subjects were treated according to clinical standards with no specific treatment protocol. The clinical standard treatment of depressed subjects consisted of drug therapy and/or psychotherapy.

\section{Follow-up procedure}

After 2 years and 5 years the subjects were invited for a follow-up assessment. This consisted of a standardized questionnaire about medical history and cognitive complaints, the MMSE, the GDS, the HDRS, the BDRS, and a neuropsychological test protocol. The diagnoses of dementia and AD were made according to the DSM-IV and 
NINCDS-ADRDA criteria (McKhann et al., 1984) by a neuropsychiatrist and a neuropsychologist, who were unaware of the results of the baseline assessment and who made their diagnosis independently of each other. If there was disagreement about the clinical diagnosis, a consensus meeting was held and if no agreement was reached the subject was considered not demented. No neuropsychological testing was done at follow-up in two subjects who were demented at follow-up because one subject was too impaired and the other had died after the diagnosis of dementia was made but before the neuropsychological test was carried out. Subjects who were demented at the 2-year follow-up were not invited for the 5-year follow-up. When separate analyses were performed with subjects who had completed the 5-year follow-up, only the demented subjects were included whose baseline assessment was at least 5 years ago.

\section{Delayed recall measure}

The delayed recall measure was selected from a neuropsychological assessment that consisted of a series of standard clinical tests covering the cognitive domains of memory, language, attention, praxis, executive functions, and intelligence, as described elsewhere (Jolles, 1986; Verhey et al., 1993). Delayed recall was tested with the Dutch version of the Auditory Verbal Learning Test (AVLT) (Brand and Jolles, 1985; Lezak, 1995). Fifteen unrelated monosyllabic words were presented five times and after each presentation the subject was asked to reproduce as many words as possible. After $20 \mathrm{~min}$, during which non-verbal tests were performed, delayed recall was tested. If the neuropsychologist considered that a subject could not perform the 15 -word version of the AVLT appropriately, a 10-word version of the test was administered (in two subjects at the 2-year follow-up and one subject at the 5-year follow-up). This score was multiplied by 1.5 to make it comparable to the others. A parallel version of the AVLT was used at follow-up.

\section{Correction of MMSE and delayed recall for age, sex, and education}

Since the MMSE and the delayed recall scores correlate with age, sex and education, we corrected the scores for these variables. The correction was based on a reference population of 1870 cognitively normal subjects older than 40 years randomly selected from a registry of general practitioners (Jolles et al., 1995; van Boxtel et al., 1998). In this population, multiple linear regression was performed with age, sex, and education entered in the first step, using $p<0.05$ as the criterion for remaining in the model. In the next step, non-linear terms and interaction terms for the significant main effects were entered. On the basis of the resulting model, an expected test score for each subject was calculated. This score was subtracted from the observed score. The residue of the delayed recall was divided by the standard deviation of the residue in the reference population to give a $z$-score. A $z$-score below zero indicated below average performance. A $z$-score of -1.28 or lower corresponds with a memory performance below the tenth percentile of the reference population. The residue of the MMSE was added to the expected MMSE of a subject with average age, sex, and education in the study population (MMSE $=28.2$ ). Both the uncorrected and corrected MMSE scores are listed in the tables, but only the corrected MMSE scores were used for the analyses. The MMSE score was not available for three subjects at baseline and these subjects were given the average MMSE score of the study population (Small et al., 1997). We chose to substitute the data in order to retain these subjects in the multivariate analysis. The analysis with and without the subjects with substituted MMSE scores yielded similar results. The three subjects without an MMSE score tended to be younger (49 years versus 61 years, $p=0.07$ ) at baseline, and had a lower GDS score $(p=0.01)$ compared to the subjects with an MMSE score. The other variables at baseline (including the $z$ score of the delayed recall and the HDRS score) were not different between the subjects with or without MMSE score at baseline.

\section{ApoE genotyping}

The apoE genotyping was performed with a polymerase chain reaction (Slooter et al., 1998; Wenham et al., 1991). Blood samples for genotyping were taken at the follow-up assessment from 1995 onwards. Therefore, no samples were available for subjects seen before 1995 or without follow-up. One subject refused to give blood. The apoE genotype was available for 44 subjects $(70 \%$ of the subjects who were seen at follow-up). Compared with the subjects who were ApoE genotyped, the subjects who were not ApoE genotyped had a lower score on the MMSE at 
Table 1. Baseline characteristics

\begin{tabular}{lccc}
\hline & $\begin{array}{c}\text { Follow-up } \\
(N=63)\end{array}$ & $\begin{array}{c}\text { No follow-up } \\
(N=11)\end{array}$ & $p$-Value \\
\hline Age & $60.1(10.4)$ & $66.9(12.8)$ & 0.06 \\
Education (years) & $10.3(3.0)$ & $11.5(3.5)$ & 0.16 \\
Sex male/female & $34 / 29$ & $5 / 6$ & 0.85 \\
HDRS & $11.1(6.3)$ & $10.3(6.1)$ & 0.69 \\
GDS & & & 1.0 \\
$-2(\%)$ & $20(32)$ & $4(36)$ & \\
$-3(\%)$ & $43(69)$ & $7(64)$ & 1.0 \\
BDRS-DL & $0.88(0.71)$ & $1.1(1.2)$ & 0.03 \\
MMSE & $27.4(1.7)$ & $26.8(1.1)$ & 0.64 \\
MMSE (corrected) & $27.7(1.6)$ & $27.4(1.1)$ & 0.34 \\
Delayed recall baseline* & $-2.0(0.6)$ & $-2.2(0.5)$ & 1.0 \\
Depressed/not depressed (\% depressed) & $22 / 41(35)$ & $4 / 7(36)$ & \\
\hline
\end{tabular}

All data are mean (SD) unless specified otherwise.

* Data expressed as $z$-score. A $z$-score below zero indicates below average performance.

baseline ( 26.9 vs $28.0, p=0.01$ ), and were more frequently demented at follow-up (42\% vs $18 \%$, $p=0.004)$. On the basis of the apoE genotype we defined a group with the apoE-e4 allele (apoE-e4+) including the genotypes e4e4 $(N=3)$ and e3e4 $(N=20)$, and a group without an APO-e4 allele (apoE-4-) including the genotypes e2e3 $(N=2)$ and e3e3 $(N=19)$.

\section{Statistical analysis}

In groups with more than 10 subjects, continuous variables were compared by means of a $t$-test. In groups with 10 or fewer subjects, continuous variables were analysed with the Mann-Whitney test corrected for ties. This test was also used to analyse the BDRS-DL data. Categorical data were analysed with a Chi-square test with continuity correction. When two or more cells had five cases or less, the two-tailed Fisher's exact test was applied. Logistic regression analysis was performed to identify variables that were predictors of outcome. At the first step age, the presence or absence of depression, and the scores on the BDRS-DL, MMSE, and delayed recall were entered and with backward step selection variables were selected that were significantly associated with outcome. The apoE genotype was not entered in the multivariate analysis because the genotype was not available for all subjects. All statistical tests were two-tailed. The significance level was set at 0.05 .

\section{RESULTS}

Of the 74 subjects included at baseline, 11 subjects $(15 \%)$ had no assessment at follow-up because they were untraceable $(N=2)$, refused to participate $(N=5)$, had died $(N=3)$, or had multiple system atrophy at follow-up $(N=1)$. Twenty-seven subjects $(36 \%)$ had a 2 -year follow-up, 33 subjects $(45 \%)$ had both a 2-year and 5-year follow-up, and three subjects $(4 \%)$ had only a 5 -year follow-up. The subjects without a follow-up assessment had similar baseline characteristics as the subjects with a follow-up assessment, except for the uncorrected MMSE score (Table 1). Nineteen subjects were demented at follow-up; they all had probable AD.

\section{Course of memory impairment}

The course of the memory impairment is shown in Fig. 1. In the 60 subjects with a 2-year follow-up, the memory performance had improved in 21 $(35 \%)$ and remained stable in $23(38 \%)$. Sixteen subjects $(27 \%)$ had $\mathrm{AD}$ at the 2-year follow-up. In the 36 subjects with a 5-year follow-up, memory performance had improved in $15(42 \%)$ and remained stable in seven $(19 \%)$. Fourteen subjects $(39 \%)$ had AD at the 5-year follow-up. One of the 10 subjects $(10 \%)$ who had improved at the 2-year follow-up showed memory impairment at the 5 -year follow-up. Seven of the 23 (33\%) subjects with persistent memory impairment but no demen- 


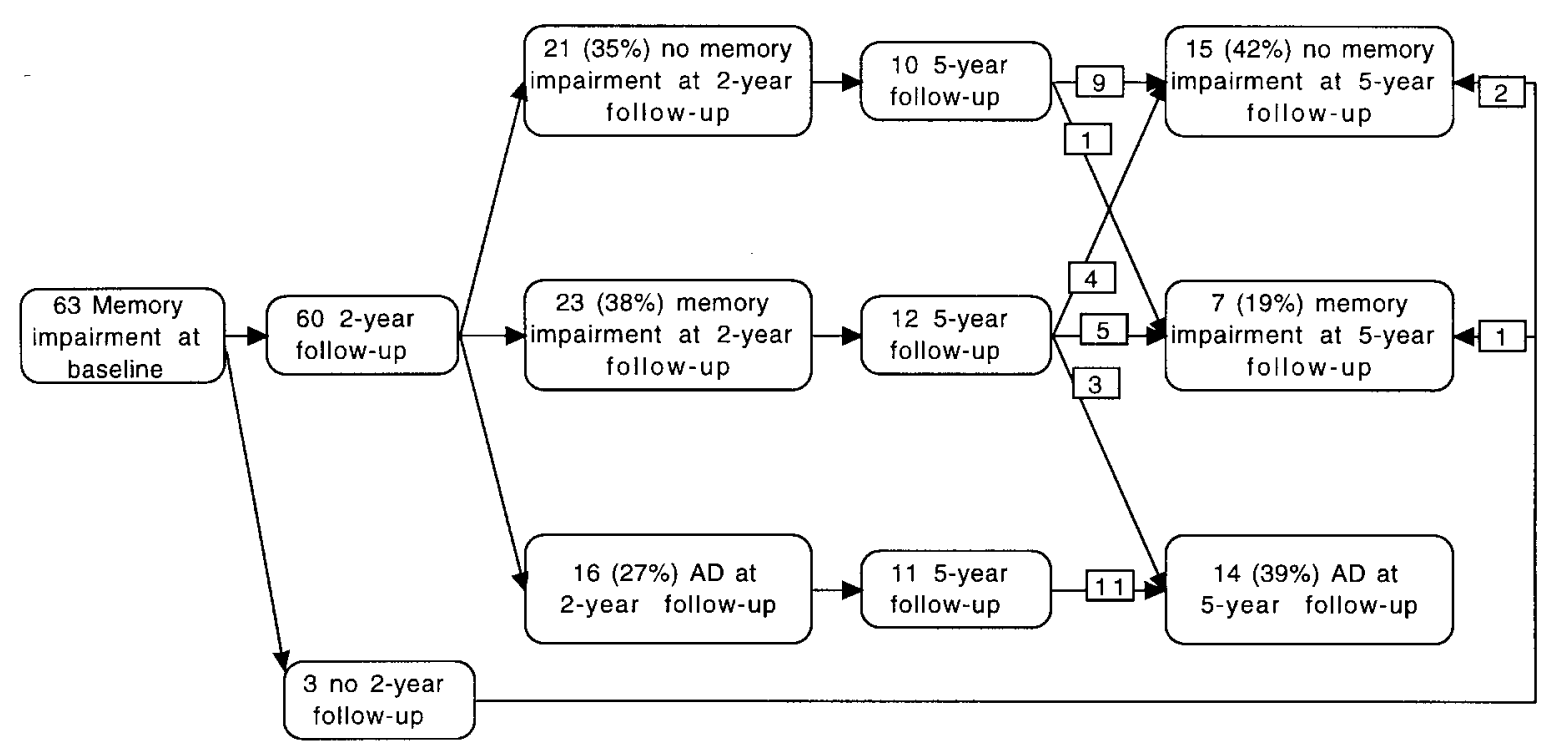

Fig. 1. Course of memory impairment. Note that subjects who had AD at the 2-year follow-up were considered to have a 5-year follow-up if the baseline assessment of these subjects was at least 5 years ago

tia at the 2-year follow-up showed improved memory function at the 5-year follow-up, while $10(42 \%)$ of these subjects remained impaired and six $(25 \%)$ had become demented.

\section{Predictors of outcome}

We classified the subjects according to the outcome at the most recent follow-up assessment (Table 2) because the differences in baseline characteristics between the groups with reversible memory impairment, persistent memory impairment, and $\mathrm{AD}$ at the 2-year follow-up were similar to the differences in baseline characteristics between these groups at the 5-year follow-up. Compared to non-demented subjects with persistent memory impairment, subjects with reversible memory impairment had higher MMSE and delayed recall scores at follow-up, and were less frequently depressed at follow-up. Subjects with reversible memory impairment had a lower age at baseline, lower GDS and BDRS-DL scores at baseline, and higher MMSE and delayed recall scores at both baseline and follow-up than did the subjects who had AD at follow-up. Subjects who were impaired but not demented at follow-up were younger and had lower GDS and BDRS-DL scores at baseline than did the subjects who had AD at follow-up. The frequency of the apoE-e4 allele or the frequency of depression at baseline was not different between the three groups.

Predictors for reversible memory impairment in the multivariate analysis were evaluated by comparing group I (reversible memory impairment) in Table 2 with group II (memory impairment at follow-up) and group III (AD at follow-up). The variables age, baseline delayed recall score, and baseline BDRS-DL score were retained in the model after backward step selection (Table 3). The BDRS-DL score was associated with reversibility in the unexpected direction. The sensitivity of the model was $58 \%$, the specificity $74 \%$, the positive predictive value (PPV) (i.e. the chance that subjects with a predicted probability for reversible memory impairment larger than 0.50 had reversible memory impairment) was $60 \%$, and the negative predictive value (NPV) (the chance that subjects with a predicted probability for reversible memory impairment lower than 0.50 did not have reversible memory impairment) was $73 \%$. Since the accuracy of the analysis could have been influenced by the fact that not all subjects completed the 5-year follow-up, we repeated the logistic regression analysis with subjects with only a 5-year followup. The variables age, baseline delayed recall score, baseline BDRS-DL score, and baseline MMSE 
Table 2. Baseline characteristics and follow-up scores according to outcome at the latest available follow-up assessment

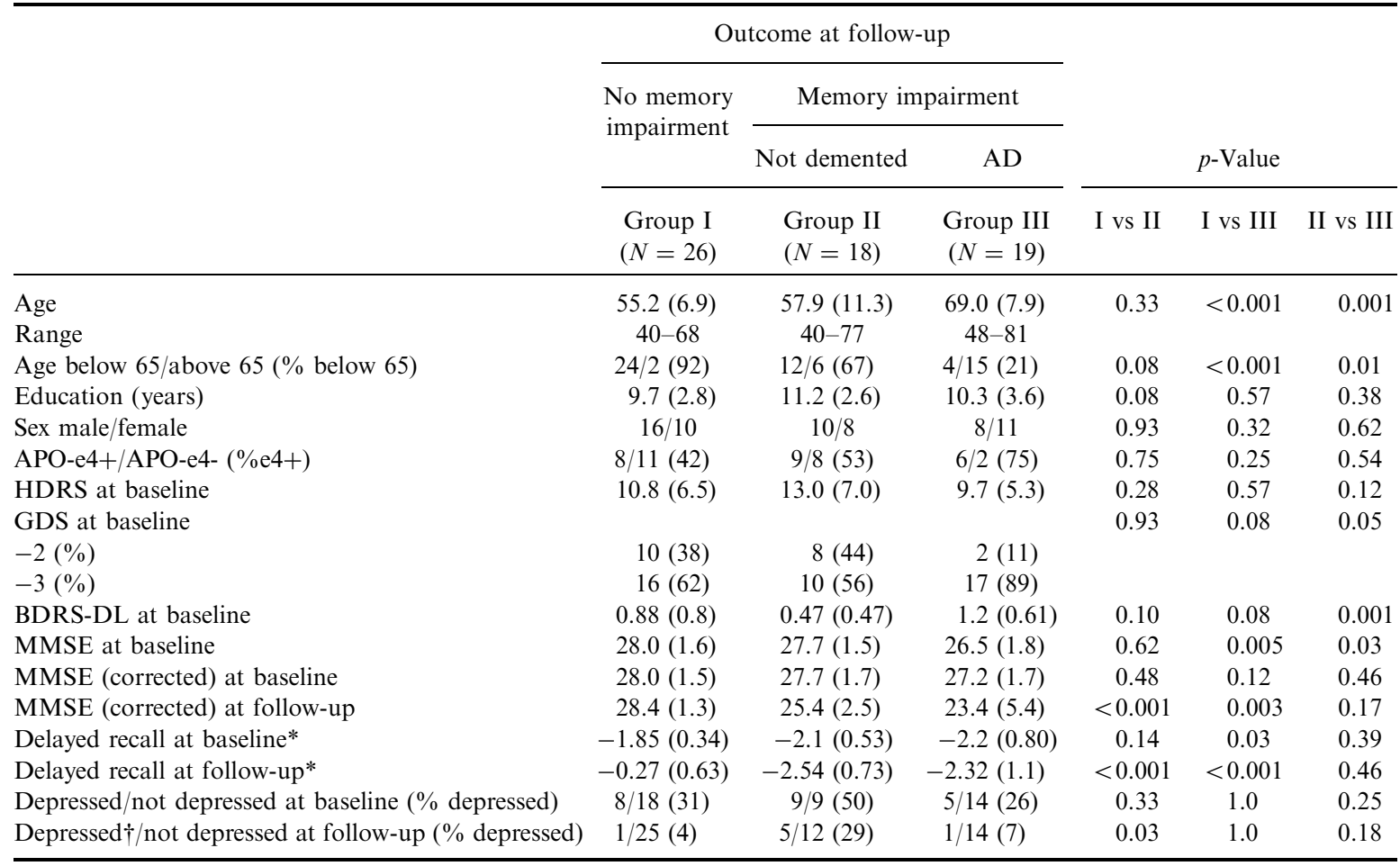

All data are means (SD) unless specified otherwise.

* Data expressed as $z$-score. A $z$-score below zero indicates below average performance.

$\uparrow$ Subjects with depression at both baseline and follow-up.

Table 3. Predictors of outcome after logistic regression with backward step selection

\begin{tabular}{|c|c|c|c|c|c|}
\hline Outcome & Selected variables (OR, CI, $p$-value) & Sensitivity & Specificity & PPV & NPV \\
\hline $\begin{array}{l}\text { Reversible memory } \\
\text { impairment }\end{array}$ & $\begin{array}{l}\text { Age }(0.87,0.8-0.9,0.001) \\
\text { Delayed recall }(4.4,1.2-16.4,0.03) \\
\text { BDRS-DL }(3.2,1.1-9.5,0.03)\end{array}$ & 54 & 73 & 58 & 69 \\
\hline $\begin{array}{l}\text { Reversible memory } \\
\text { impairment (only subjects } \\
\text { with a } 5 \text {-year follow-up) }\end{array}$ & $\begin{array}{l}\text { Age }(0.84,0.7-1.0,0.01) \\
\text { Delayed recall }(11.3,1.0-120,0.05) \\
\text { BDRS-DL }(6.8,0.9-3.7,0.07) \\
\operatorname{MMSE}(1.8,0.9-52.5,0.09)\end{array}$ & 87 & 76 & 72 & 89 \\
\hline $\mathrm{AD}$ & $\begin{array}{l}\text { Age }(1.2,1.1-1.3,0.001) \\
\text { Delayed recall }(0.35,0.1-1.2,0.09) \\
\text { MMSE }(0.65,0.4-1.0,0.07)\end{array}$ & 74 & 89 & 74 & 89 \\
\hline $\begin{array}{l}\text { AD (only subjects with a } \\
\text { 5-year follow-up) }\end{array}$ & $\begin{array}{l}\text { Age }(1.3,1.1-1.5,0.003) \\
\operatorname{MMSE}(0.40,0.2-1.0,0.04)\end{array}$ & 93 & 86 & 81 & 95 \\
\hline
\end{tabular}

$\mathrm{OR}=$ odds ratio per unit change; $\mathrm{CI}=$ confidence interval; $\mathrm{PPV}=$ positive predictive value; $\mathrm{NPV}=$ negative predictive value. 
score were selected with backward step selection (Table 3). Again, the BDRS-DL score was associated with reversibility in the unexpected direction. The predictive accuracy was better than that of the model with all subjects (Table 3 ).

Predictors of $\mathrm{AD}$ in the multivariate analysis were evaluated by comparing group III (AD at follow-up) in Table 2 with group I (reversible memory impairment) and group II (memory impairment at follow-up). The variables age, baseline delayed recall score, and baseline MMSE score were retained in the model after backward step selection (Table 3). The sensitivity of the model was $76 \%$, the specificity $89 \%$, the PPV $76 \%$, and the NPV $85 \%$. When the analysis was repeated with only subjects with a 5-year follow-up, the variables age and baseline MMSE score were retained in the model after backward step selection and the predictive accuracy was higher than that of the model with all subjects (Table 3).

Decision rules for identifying subjects with reversible memory impairment and subjects with dementia at follow-up

In order to develop decision rules that can be easily used in clinical practice to predict outcome, we dichotomized all variables. The cut-off points were established such that the outcome could be predicted with a high positive predictive value. Twenty-two of the 26 subjects $(85 \%)$ with reversible memory impairment were younger than 65 , had a delayed recall score between the first and the tenth percentile, and a corrected MMSE score above 26.5. Also six subjects with persistent memory impairment or AD fulfilled these criteria (the PPV was 79\%). Thirteen of the 19 subjects $(68 \%)$ with $\mathrm{AD}$ at follow-up were older than 65 and had a BDRS-DL score at base $\geqslant 1$. Three nondemented subjects fulfilled these criteria (the PPV was $81 \%$ ).

The decision rules for reversible memory impairment were based on corrected MMSE and delayed recall scores. Since these corrected scores may not be available, we also used uncorrected scores. Fourteen of the 26 subjects (54\%) with reversible memory impairment were younger than 65 years, had a delayed recall of $\geqslant 4$ words, and had a MMSE score $\geqslant 28$. Four subjects with persistent memory impairment or AD at follow-up fulfilled these criteria (the PPV was $78 \%$ ).

\section{DISCUSSION}

The main conclusion of this study is that objective memory impairment in non-demented subjects is reversible $(42 \%)$ as often as it is a precursor of subsequent AD (39\%). Age and the baseline MMSE and delayed recall scores were the best predictors of outcome.

Our study is unique for several reasons. First, there have been no previous longitudinal studies that focused on the prediction of reversible memory impairment. Second, we followed memory-impaired subjects for up to 5 years, which is longer than in most other studies. Third, we also included younger subjects in the age range 40-60 years, which enables us to generalize the results more than in other studies. Fourth, we investigated not only cognitive measures and age as predictors but also a functional measure, a genetic marker, and the presence of depression.

This is the first study that shows that in a clinical setting the severity of the memory impairment, age, a low score on the MMSE, and the degree of functional impairment are associated with an increased risk of AD in non-demented elderly subjects with memory impairment. These findings corroborate the findings from population-based studies (Braekhus et al., 1995; Brayne et al., 1997; Jacobs et al., 1995; Linn et al., 1995; Ott et al., 1998). The findings that functional impairment was associated with reversibility of memory impairment in the wrong direction in the multivariate analysis probably resulted from the fact that the BDRS-DL score tended to be lower in subjects with persistent memory impairment than in subjects with reversible memory impairment (Table 2). The relation between depression and the outcome of memory impairment was not straightforward. In one third of the subjects who were depressed at baseline, the depression improved together with the memory impairment $(N=7)$, in one third both the depression and the memory impairment persisted at follow-up $(N=6)$, and in one third the depression improved while the cognitive impairment remained or progressed to $\operatorname{AD}(N=6)$. The latter group was at baseline older than the other groups [66 years vs 55 years $(p=0.04)$ and 56 years $(p=0.15)$ respectively]. Thus, when both moderately severe depression and memory impairment are present, the memory impairment is not necessarily secondary to the depression, and this is probably especially true in elderly subjects (O'Connor et al., 1990). We expected that the apoE-e4 allele would 
be strongly related with $\mathrm{AD}$ or persistent memory impairment. However, a substantial number of the subjects with reversible memory impairment appeared to be carriers of the apoE-e4 allele. All these subjects were younger than 65 years. This finding is of interest because it suggests that only in subjects older than 65 is the apoE-e4 allele associated with persistent memory impairment or AD (Coria et al., 1995; Petersen et al., 1995). The apoE-e4 allele was frequently found in subjects who developed dementia at follow-up, but the apoE-e4 allele frequency in the demented subjects was not significantly different from that of the other subjects, probably because the apoE genotype was not determined in all demented subjects.

In almost $50 \%$ of the subjects with reversible memory impairment, the improvement of cognitive functioning may have resulted from improvement of depression. In the other subjects, the improvement could be due to improvement of subsyndromal depression or stress, that was caused, for example, by bereavement, co-morbid disorders, or pain. We did not, however, investigate these possible causes of reversible memory impairment. In addition, improvement could also have resulted from learning effects or regression to the mean. Nineteen per cent of the subjects continued to have memory impairment after 5 years but had not developed AD. These subjects were relatively young and had little functional impairment at baseline. Depression was common at baseline and persisted in more than $50 \%$ of the subjects. This may indicate that in these subjects the memory impairment is related to depression, but it can not be excluded that these subjects would develop AD later on. The apoE-e4 allele frequency was high, suggesting that some of the subjects would develop $\mathrm{AD}$ after the follow-up period. In $\mathrm{AD}$, severe memory impairment can exist up to 13 years before other cognitive deficits develop (Didic et al., 1998).

In order to translate these findings to clinical practice, we tried to formulate some decision rules. Clearly, these rules need cross-validation in our own population and in different settings. The decision rules were not based on the same variables that were selected by the multivariate analyses. This probably resulted from the fact that we made use of dichotomized scores in formulating the decision rules. One of the most important factors in predicting outcome was age. Typically, subjects with reversible memory impairment were younger than 65 years and subjects with AD at follow-up were older than 65 years. When subjects older than
65 years also experienced difficulties with activities of daily living there was a high risk $(81 \%)$ of subsequent $\mathrm{AD}$. The combination of age below 65 , a delayed recall of $\geqslant 4$ words, and a MMSE score $\geqslant 28$ indicated a high chance $(78 \%)$ that the memory impairment was reversible. The sensitivity of these decision rules was low (less than 70\%), which means that the baseline characteristics of subjects with reversible memory impairment or AD at follow-up are heterogeneous. This lack of a simple profile of subjects with reversible memory impairment or $\mathrm{AD}$ at follow-up implies that information from different sources is important to predict outcome. The sensitivity and positive preictive value may be further increased by using biological markers of $\mathrm{AD}$, such as hippocampal atrophy (de Leon et al., 1993; Visser et al., 1999).

A limitation of the study is the fact that not all subjects completed the 5-year follow-up. The reason why not all subjects had a 5-year followup was that not all subjects were long enough in the study. As can be seen in Fig. 1, the outcome of some subjects who had memory impairments but who were not demented after 2 years changed after 5 years. We therefore repeated the analyses with only subjects with 5-year follow-up data. This had the disadvantage that there were few subjects. The outcome of the logistic regression model and the decision rules are sample-dependent and may therefore not apply in other settings. There may be other causes of reversible memory impairment such as medications, hypothyroid or hyperthyroid function, or vitamin deficiency, but these conditions were excluded at baseline.

\section{CONCLUSION}

Memory impairment is often reversible, and for this reason memory impairment alone is not sufficient cause to consider a subject as preclinically demented. Predictive accuracy can be increased by taking into consideration simple measures such as age, the scores on the MMSE and delayed recall, and the degree of functional impairment. When both depression and memory impairment are present, the memory impairment is not necessarily secondary to the depression, but both can be the first symptoms of AD. Memory impairment may even be reversible in carriers of the apoE-e4 allele. 


\section{ACKNOWLEDGEMENTS}

The authors thank Drs Monique de Lugt and Nico Roozendal for their help in the data collection and data management, Sally Serneels for performing the ApoE genotyping, and Dr Jane Sykes for her linguistic advice. The ApoE genotyping was supported by a grant of the Fund of Scientific Research Flanders (FWO) and a special research grant of the University of Antwerp (UIA). Marc Cruts is a postdoctoral fellow of the FWO.

\section{REFERENCES}

Alexopoulos GS, Meyers BS, Young JC, Mattis S, Kakuma T. 1993. The course of geriatric depression with "reversible dementia": a controlled study. Am. J. Psychiat. 150(11): 1693-1699.

Almkvist O, Basun H, Bäckman L, Herlitz A, Lannfelt L, Small B, Viitanen M, Wahlund L, Winblad B. 1998. Mild cognitive impairment - an early stage of Alzheimer's disease? J. Neural Transm. 54(Suppl.): 21-29.

American Psychiatric Association. 1994. Diagnostic and Statistical Manual of Mental Disorders, IVth edn. American Psychiatric Association: Washington, DC.

Blessed G, Tomlinson B, Roth M. 1968. The association between quantitative measures of dementia and of senile change in the cerebral grey matter of elderly subjects. Br. J. Psychol. 225: 797-811.

Bowen J, Teri L, Kukull W, McCormick W, McCurry S, Larson E. 1997. Progression to dementia in patients with isolated memory loss. Lancet 349: 763-765.

Braekhus A, Laake K, Engedal K. 1995. A low, 'normal' score on the Mini-Mental State Examination predicts development of dementia after three years. JAGS $\mathbf{4 3}$ : 656-661.

Brand N, Jolles J. 1985. Learning and retrieval rates of words presented auditory and visually. J. Gen. Psychol. 112: 201-210.

Brayne C, Best N, Muir M, Richards S-J, Gill C. 1997. Five-year incidence and prediction of dementia and cognitive decline in a population sample of women aged 70-79 at baseline. Int. J. Geriatr. Psychiat. 12: $1107-1118$.

Christensen H, Griffiths K, MacKinnon A, Jacomb P. 1997. A quantitative review of cognitive deficits in depression and Alzheimer-type dementia. JINS 3: 631-651.

Coria F, Rubio I, Bayon C, Santaengracia N, RodriquezArtalejo F. 1995. Apolipoprotein E allele variants predict dementia in elderly people with memory impairment. Eur. J. Neurol. 2: 191-193.

de Leon M, George A, Convit A, Tarshish C, McRae T, De Santi S, Smith G, Ferris S, Noz M, Rusinek H. 1993. The radiologic prediction of Alzheimer's disease: the atrophic hippocampal formation. AJNR 14: 897-906.

Didic M, Chérif A, Gambarelli D, Poncet M, Boudouresques J. 1998. A permanent pure amnestic syndrome of insidious onset related to Alzheimer's disease. Ann. Neurol. 43: 526-530.

Folstein M, Folstein S, McHugh P. 1975. "Mini-Mental State": a practical method for grading the cognitive state of patients for the clinician. J. Psych. Res. 12: 189-198.

Hamilton M. 1960. A rating scale for depression. $J$. Neurol. Neurosurg. Psychiat. 23: 56-62.

Hill CD, Stoudemire A, Morris R, Martino-Saltzman D, Markwalter HR. 1992. Similarities and differences in memory deficits in patients with primary dementia and depression-related cognitive dysfunction. J. Neuropsychiat. Clin. Neurosci. 5: 277-282.

Jacobs D, Sano M, Dooneief G, Marder K, Bell K, Stern Y. 1995. Neuropsychological detection and characterization of preclinical Alzheimer's disease. Neurology 45: $957-962$.

Jolles J. 1986. The early diagnosis of dementia: a possible contribution of neuropsychology. Aging of the Brain, Gispen W, Traber J (eds); Springer Verlag: Berlin; pp. $84-100$.

Jolles J, Houx P, van Boxtel M, Ponds R. 1995. Maastricht Aging Study: Determinants of Cognitive Aging. Neuropsych Publishers: Maastricht.

Levy R. 1994. Aging-associated cognitive decline. Int. Psychogeriatr. 6(1): 63-68.

Lezak M. 1995. Neuropsychological Assessment, 3rd edn. Oxford University Press: New York.

Linn R, Wolf P, Bachman D, Knoefel J, Cobb J, Belanger A, Kaplan E, D’Agostino R. 1995. The 'preclinical phase' of probable Alzheimer's disease. Arch. Neurol. 52: 485-490.

McKhann G, Drachman D, Folstein M, Katzman R, Price D, Stadlan EM. 1984. Clinical diagnoses of Alzheimer's disease: report of the NINCDS-ADRDA Work-Group under the auspices of the Department of Health and Human Services Task Force on Alzheimer's disease. Neurology 34: 939-944.

O'Brien J, Beats B, Hill K, Howard R, Sahakian B, Levy R. 1992. Do subjective memory complaints precede dementia? A three-year follow-up of patients with supposed 'benign senescent forgetfulness'. Int. J. Geriatr. Psychiat. 7: 481-486.

O'Connor D, Pollit P, Hyde J, Fellows J, Miller N, Roth M. 1990. A follow-up of dementia diagnosed in the community using the Cambridge Mental Disorders of the elderly examination. Acta Psychiat. Scand. 83: $41-45$.

Ott A, Breteler M, van Harskamp F, Stijnen T, Hofman A. 1998. Incidence and risk of dementia. The Rotterdam Study. Am. J. Epidemiol. 147: 574-580.

Petersen R, Smith G, Ivnik R, Tangalos E, Schaid D, Thibodeau S, Kokmen E, Waring S, Kurland L. 1995. Apolipoprotein E status as a predictor of the devel- 
opment of Alzheimer's disease in memory impaired individuals. JAMA 273: 1274-1278.

Reisberg B, Ferris S, De Leon M, Crook T. 1982. The global deterioration scale for assessment of primary degenerative dementia. Am. J. Psychiat. 139: $1136-1139$.

Slooter A, Cruts M, Kalmijn S, Hofman A, Breteler M, Van Broeckhoven C, van Duijn C. 1998. Risk estimates of dementia by apolipoprotein $\mathrm{E}$ genotypes from a population-based incidence study: The Rotterdam study. Arch. Neurol. 55: 964-968.

Small B, Herlitz L, Fratiglioni L, Almkvist O, Bäckman L. 1997. Cognitive predictors of incident Alzheimer's disease: a prospective longitudinal study. Neuropsychol. 11: 413-420.

Smith G, Petersen R, Parisi J, Ivnik R, Kokmen E, Tangalos E, Waring S. 1996. Definition, course, and outcome of mild cognitive impairment. Aging, Neuropsychol. Cognition 3: 141-147.

Tierney M, Szalai J, Snow W, Fisher R, Nores A, Nadon G, Dunn E, St George-Hyslop P. 1996. Prediction of probable Alzheimer's disease in memory impaired patients. Neurology 46: 661-665.

van Boxtel M, Buntinx F, Houx P, Metsemakers J, Knottnerus A, Jolles J. 1998. The relation between morbidity and cognitive performance in a normal aging population. J. Gerontol. Med. Sci. 53A: M146-M154.

Verhey F, Jolles J, Ponds R, Rozendaal N, Plugge L, de Vet H, Vreeling F, van de Lugt P. 1993. Diagnosing dementia: a comparison between a monodisciplinary and multidisciplinary approach. J. Neuropsychiat. Clin. Neurosci. 5: 78-85.

Visser P, Scheltens P, Verhey F, Schmand B, Launer L, Jolles J, Jonker C. 1999. Predictive value of medical temporal lobe volume for cognitive decline in community dwelling elderly. J. Neurol. 246: 477-485.

Wenham P, Price W, Blundell G. 1991. Apolipoprotein $\mathrm{E}$ genotyping by one-stage PCR. Lancet 337: $1158-1159$. 